\title{
Coacervação complexa: uma técnica para a encapsulação de probióticos
}

\author{
Complex coacervation: a technique for encapsulation of probiotics
}

\author{
Thaiane Marques da Silva ${ }^{1 *}$, Luiza Zancan Rodrigues ${ }^{2}$, Cristiane Franco Codevilla, \\ Cristiane Bona da Silva ${ }^{3}$, Cristiano Ragagnin de Menezes ${ }^{4}$ \\ ${ }^{1}$ Mestranda em Ciência e Tecnologia dos Alimentos, Universidade Federal de Santa Maria, RS, Brasil \\ ${ }^{2}$ Graduanda em Tecnologia em Alimentos, Universidade Federal de Santa Maria, RS, Brasil \\ ${ }^{3}$ Doutora em Ciências Farmacêuticas, Universidade Federal de Santa Maria, RS, Brasil \\ ${ }^{4}$ Doutor em Ciência de Alimentos, Universidade Federal de Santa Maria, RS, Brasil
}

\begin{abstract}
Resumo
A microencapsulação consiste na proteção de um composto e modulação de sua liberação e, atualmente, varias técnicas estão disponíveis e entre elas destaca-se a coacervação complexa. A técnica de coacervação complexa envolve a associação de dois polímeros e apresenta algumas vantagens frente a outras técnicas como a possibilidade de se trabalhar com biopolímeros, a ausência de solvente orgânico e condições brandas de temperatura no processamento. Os alimentos funcionais contendo bactérias probióticas estão se tornando cada vez mais populares no mercado devido aos efeitos benéficos à saúde atribuídos aos probióticos. No entanto, esses microrganismos são sensíveis a vários fatores encontrados no meio em que estão expostos, principalmente ao tratogastrointestinal, bem como às condiçães de armazenamento. Assim, a microencapsulação surge como uma alternativa de proteção e liberação controlada para os probióticos. No entanto, fatores como temperatura, concentração dos hidrocolóides e $p H$, principalmente, podem influenciar na formação das microcápsulas. Para a encapsulação de probióticos, ainda não existem muitos estudos relacionados, entretanto, de acordo com resultados encontrados, essa técnica pode ser considerada promissora para esses microrganismos. Nesse sentido, este artigo de revisão, tem por objetivo abordar os principais aspectos tecnológicos relacionados à microencapsulação de probióticos pela técnica de coacervação complexa, bem como os parâmetros relacionados à técnica e seu potencial de aplicação.
\end{abstract}

Palavras-chave: Probióticos. Alimentos funcionais. Encapsulação. Coacervação complexa.

\begin{abstract}
Microencapsulation is the protection of a compound and modulation of its release and now, several techniques are available and among them there is the complex coacervation. The complex coacervation technique involves the association of two polymers and presents some advantages over other techniques such as the possibility of working with biopolymers, the absence of organic solvent and temperature conditions in mild processing. Functional foods containing probiotic bacteria are becoming increasingly popular in the market due to the beneficial health effects attributed to probiotics. However, these microorganisms are sensitive to various factors found in the environment that are exposed primarily to tratogastrointestinal and storage conditions. Thus, the microencapsulation is an alternative protection and controlled release for probiotics. However, factors such as temperature, $\mathrm{pH}$ and concentration of the hydrocolloid, particularly, can influence the formation of microcapsules. For the encapsulation of probiotics, although there are many related studies, however, according to these results, this technique can be regarded as promising for these microorganisms. Thus, this review article aims to address the key technological aspects related to microencapsulation of probiotics by the complex coacervation technique as well as the parameters related to the technique and its application potential.
\end{abstract}

Keywords: Probiotics. Functional foods. Encapsulation. Complex coacervation. 


\section{Introdução}

A microencapsulação é uma tecnologia inovadora que protege os produtos de condições ambientais desfavoráveis e prolonga a vida útil (GOUIN, 2004; FAVARO-TRINDADE et al., 2008).

Um procedimento simples e conveniente para a formação de microcápsulas é o método conhecido como coacervação complexa. A coacervação complexa consiste basicamente na combinação de duas soluções hidrocolóides de cargas opostas causando interação e precipitação dos polímeros complexos, que juntamente com os microrganismos, resultará na formação de microcápsulas, resultado das interações eletrostáticas, pela alteração do pH da fase aquosa (SILVA et al., 2011; SHOJI et al., 2013).

Além disso, a coacervação é uma tecnologia de encapsulação altamente promissora pela sua elevada eficiência de encapsulação (acima de 99\%) e a facilidade de liberação controlada de seu conteúdo por esforço mecânico, temperatura ou mudanças no pH (GOUIN 2004).

Atualmente, estudos têm demonstrado que a população está cada vez mais consciente da relação entre a dieta e o desenvolvimento de doenças e que os alimentos podem contribuir na prevenção de muitas destas, sendo assim denominados alimentos funcionais. Para serem considerados funcionais, os alimentos devem além de contribuir para a nutrição básica, possuir componentes fisiologicamente ativos. Entre os alimentos funcionais, considerável atenção tem sido dada às bactérias probióticas, pelos possíveis efeitos benéficos que podem trazer à saúde como prevenção de infecções urogenitais por patógenos, atividade antimicrobiana, diminuição do risco de desenvolvimento de tumores por estimulação do sistema imunológico, melhoramento da intolerância à lactose e diminuição dos níveis de colesterol sérico (FULLER, 1989; OLIVEIRA, 2006).

No entanto, as bactérias probióticas na forma livre podem ser sensíveis aos processos empregados na produção de alimentos, além disso, podem não permanecer viáveis no produto até o momento do consumo ou não serem capazes de sobreviver à passagem pelo trato gastrintestinal. Dessa forma, a microencapsulação tem sido empregada com o intuito de proteger as bactérias probióticas de condições adversas do meio externo e do trato gastrintestinal e, consequentemente, fornecer essas bactérias em quantidades suficientes para que exerçam seus efeitos benéficos, mantendo a sobrevivência destas durante a vida útil. Nesse sentido, a encapsulação pode promover a liberação controlada e otimizar o fornecimento dos probióticos no local de ação, potenciando, dessa forma, a eficácia da respectiva cepa probiótica. Esse processo também pode impedir esses microrganismos de se multiplicarem nos alimentos e, consequentemente, alterar suas características sensoriais (KOMATSU, BURITI \& SAAD, 2008; RANADHEERA; BAINES; ADAMS, 2010; BURGAIN et al., 2011; CHÁVARRI; MARAÑÓN; VILLARÁN, 2012; SHOJI et al., 2013).
Diante do exposto, esse artigo de revisão tem por objetivo abordar os aspectos relacionados à encapsulação de microrganismos probióticos pela técnica de coacervação complexa.

\section{Probióticos}

Atualmente, os probióticos são definidos como microrganismos vivos, administrados em quantidades adequadas, que conferem benefícios à saúde do hospedeiro (FOOD AND AGRICULTURE ORGANIZATION OF UNITED NATIONS; WORLD HEALTH ORGANIZATION, 2001).

Estes microrganismos trazem uma série de efeitos benéficos como efeitos antagônicos, competição e efeitos imunológicos, resultando em um aumento da resistência contra patógenos. Dessa forma, a utilização de culturas bacterianas probióticas estimula a multiplicação de bactérias benéficas, em detrimento à proliferação de bactérias potencialmente prejudiciais, reforçando os mecanismos naturais de defesa do hospedeiro (SAAD, 2006).

As bactérias mais frequentemente empregadas como suplementos probióticos utilizados em alimentos, são as bactérias pertencentes aos gêneros Lactobacillus e Bifidobacterium e, em menor escala, Enterococcus faecium, uma vez que elas têm sido isoladas de todas as porções do trato gastrintestinal do humano saudável. No Brasil são aprovadas para uso como probióticos as espécies L. acidophilus, L. casei shirota, L. casei variedade rhamnosus, L. casei variedade defensis, L. paracasei, Lactococcus lactis, Bifidobacterium bifidum, B. animallis (incluindo a subespécie B. lactis), B. longum e Enterococcus faecium (Figura 1) (SAAD, 2006; BRASIL, 2008).

Outro ponto importante é a recomendação diária do consumo de probióticos para que determinados

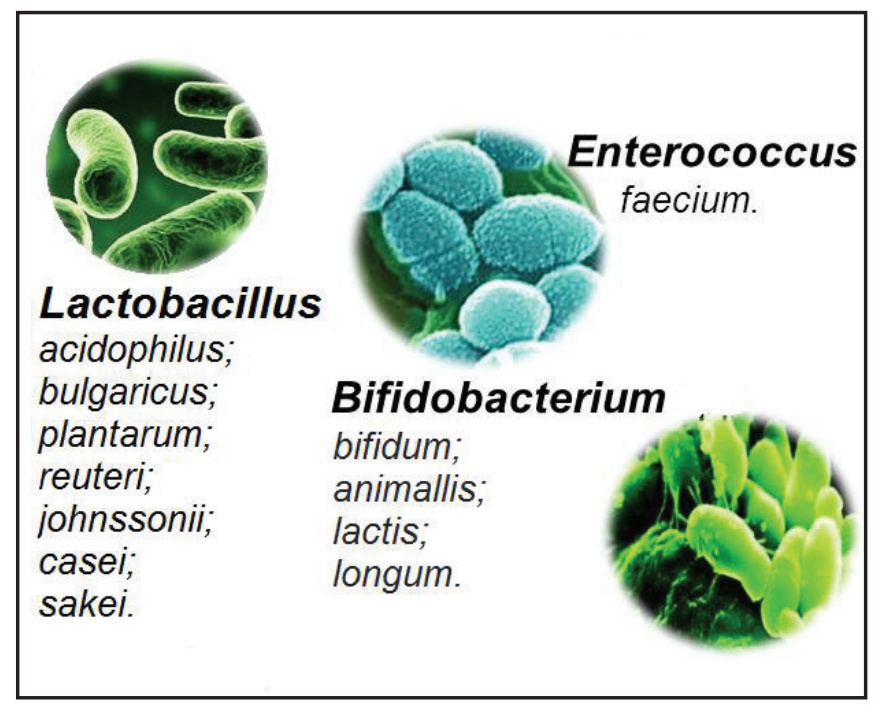

Figura 1 - Gêneros de bactérias utilizadas como probióticos e suas respectivas espécies Fonte: DAIRIKI (2013) 
benefícios ocorram. A legislação brasileira recomenda a ingestão diária de 108 - 109 UFC/g, entretanto, valores menores podem ser aceitos desde que sua eficiência seja comprovada (BRASIL, 2008).

\section{Encapsulação de probióticos}

A microencapsulação consiste no aprisionamento de pequenas partículas, também conhecidas como núcleo, dentro de um material secundário, também conhecido como matriz ou reservatório, formando pequenas cápsulas (AUGUSTIN; HEMAR, 2009).

Dessa forma, a microencapsulação é uma técnica emergente para o acondicionamento de biomoléculas ou células em uma matriz que pode proporcionar uma característica de liberação desejada e uma barreira física contra condições ambientais adversas (CHITPRASERT, SUDSAI \& RODKLONGTAN, 2012).

Atualmente, a técnica de encapsulação está sendo muito utilizada na indústria de alimentos com o intuito de proteger compostos bioativos, como o controle da reação oxidante, mascarando sabores, odores e cores, proporcionando liberação controlada, prolongando a vida de prateleira, etc. E entre os compostos bioativos mais encapsulados estão probióticos (BURGAIN et al., 2011).

Nesse sentido, a encapsulação pode promover a liberação controlada e otimizar o fornecimento dos probióticos no local de ação, potenciando, dessa forma, a eficácia da respectiva cepa probiótica. Esse processo também pode impedir esses microrganismos de se multiplicarem nos alimentos e, consequentemente, alterar suas características sensoriais. Além disso, a matriz alimentar de encapsulação deve atuar como um tampão durante o armazenamento, bem como no estômago, até o probiótico ser entregue no trato gastrointestinal, juntamente oferecendo uma proteção durante o processamento térmico (RANADHEERA; BAINES; ADAMS, 2010; BURGAIN et al., 2011; CHÁVARRI; MARAÑÓN; VILLARÁN, 2012; SHOJI et al., 2013).

Dessa maneira, a encapsulação pode proteger ingredientes alimentícios sensíveis (sabores, óleos poliinsaturados, vitaminas) frente ao calor, umidade e $\mathrm{pH}$ até o momento em que serão consumidos. Além disso, a encapsulação pode oferecer benefícios na liberação de muitos produtos, como agentes aromatizantes em gomas de mascar que são liberados na mastigação, agentes da fermentação, que são liberados durante o cozimento e bactérias probióticas, que são protegidos do ambiente gástrico durante a passagem e liberados no intestino delgado (AUGUSTIN; HEMAR, 2009).

Na indústria de alimentos a encapsulação está sendo utilizada para fornecer uma variedade de ingredientes alimentícios dentro de pequenas cápsulas quando a adição direta do ingrediente compromete a qualidade do produto fabricado. À medida que o núcleo é protegido de outros componentes presentes no alimento, bem como do meio ambiente, a encapsulação pode melhorar o conteúdo nutricional do alimento sem afetar o sabor, aroma ou textura, mascarar sabores indesejáveis, aumentar a vida de prateleira e a estabilidade do ingrediente ativo e do produto alimentar (AUGUSTIN; HEMAR, 2009).

Entre os ingredientes alimentares que estão sendo encapsulados estão os agentes aromatizantes (adoçantes, condimentos, especiarias, óleos essenciais), ácidos alimentares e bases (cítrico, bicarbonato de sódio), lipídios (óleos vegetais, gordura láctea), aditivos alimentares (conservantes, pigmentos), sais minerais (sais de cálcio e ferro), (por exemplo, vitaminas caroteno). Mais recentemente, há um crescente interesse na encapsulação de ingredientes bioativos, particularmente óleos ômega-3, fitonutrientes planta e bactérias probióticas devido aos seus benefícios à saúde associados. Todos estes ingredientes alimentícios variam muito em suas propriedades químicas, físicas e fisiológicas. A retenção do ingrediente alimentício, dentro de uma microcápsula e a sua estabilidade dependem de muitos fatores, como a natureza química, o peso molecular, a polaridade e a volatilidade do ingrediente, a sua interação com o material de matriz e a sua localização dentro da estrutura da microcápsula, até sua liberação ser desencadeada por um estímulo externo (AUGUSTIN; HEMAR, 2009).

\subsection{Principais técnicas utilizadas para a encap- sulação de probióticos}

Várias tecnologias podem ser aplicadas para a encapsulação de probiótico e cada uma delas proporciona microcápsulas com características diferentes em termos de tamanho de partículas e do tipo de cápsula. Além disso, a escolha do método de encapsulação é um ponto importante, pois depende de uma série de fatores, como: tamanho de partícula requerido, propriedades físicas e químicas do material ativo e do agente encapsulante, aplicação do produto final, mecanismos desejados de liberação e custo (AZEREDO, 2005; BURGAIN et al., 2011).

De acordo com Suave (2006) a diferença básica entre os métodos existentes está no tipo de envolvimento ou aprisionamento do material ativo pelo agente encapsulante, visto que a combinação entre o material e o agente ativo pode ser de natureza física, química ou físico-química.

Na Tabela 1 estão descritos os métodos de encapsulação seguidos das respectivas técnicas utilizadas.

\subsection{Principais materiais utilizados para a en- capsulação de probióticos}

Vários estudos têm mostrado que a microencapsulação tem sido bem sucedida no revestimento de bactérias utilizando vários materiais (SULTANA et al., 2000). Segundo Suave (2006) o material encapsulante é selecionado em função das propriedades físicas e químicas do agente 
Tabela 1 - Métodos e técnicas de encapsulação

\begin{tabular}{ll}
\hline Encapsulação & Técnicas \\
\hline Métodos & Spray drying, spray cooling, pulverização em \\
\hline Físicos & banho térmico, leito fluidizado, extrusão \\
& centrífuga com múltiplos orifícios, co- \\
& cristalização e liofilização. \\
Químicos & Inclusão molecular e polimerização \\
Físico-químicos & interfacial. \\
& Coacervação ou separação de fases, \\
& emulsificação seguida de evaporação do \\
& solvente, pulverização em agente formador de \\
& reticulação e envolvimento lipossômico.
\end{tabular}

Fonte: SUAVE (2006)

ativo, da aplicação pretendida e do método utilizado para formar as micropartículas. Além disso, deve apresentar baixa viscosidade em concentrações elevadas e ser de fácil manipulação durante o processo; possuir baixa higroscopicidade, para facilitar a manipulação e evitar aglomeração; não ser reativo com o material a ser encapsulado; ter habilidade de selar e segurar o material ativo dentro da estrutura da cápsula; liberar completamente o solvente ou outros materiais utilizados durante o processo de encapsulação; proporcionar máxima proteção ao material ativo contra condições adversas, tais como luz, pH, oxigênio e ingredientes reativos; ser solúvel em solventes comumente usados; possuir as propriedades desejadas de liberação do material ativo; não apresentar sabor desagradável no caso de consumo oral; e ser econômico.

Na Tabela 2 estão listados os materiais encapsulantes mais utilizados na encapsulação de probióticos.

\section{Encapsulação de probióticos por coacer- vação complexa}

A coacervação complexa pode ser definida como o processo no qual um complexo polieletrolítico é formado. Este processo requer a mistura de dois colóides com ajuste de $\mathrm{pH}$ ao qual os dois polímeros de cargas opostas são conduzidos a uma separação de fases e formação de partículas sólidas ou gotículas de líquido fechadas (Figura 2) (CHÁVARRI; MARAÑÓN; VILLARÁN, 2012).

Esses coacervados complexos têm sido utilizados por vários segmentos como indústrias farmacêuticas, químicas, de cosméticos e de alimentos. Na indústria de alimentos tem sido utilizada para a encapsulação de componentes alimentares ativos tais como aromatizantes, agentes ativos solúveis em água, como os probióticos e óleos (AUGUSTIN; HEMAR, 2009; ALVIM; GROSSO, 2010).

Muitos fatores, incluindo o tipo de biopolímero (massa molar, a flexibilidade e a carga), o pH, a força iônica, a concentração e a relação entre os biopolímeros afeta a força da interação entre os biopolímeros e a natureza do complexo formado. Embora interações eletrostáticas sejam consideradas importantes na condução da interação entre os biopolímeros de carga oposta, interações hidrofóbicas e ligação de hidrogênio também podem contribuir de forma significativa para a formação do complexo (AUGUSTIN; HEMAR, 2009).

Além disso, os coacervados são formados quando uma proteína a um $\mathrm{pH}$ abaixo do seu ponto isoelétrico (isto é, quando carrega carga positiva) é misturado com um poliânion (Figura 3). Exemplos disso são misturas de proteína de soro de leite ou de gelatina com goma arábica a um $\mathrm{pH}$ abaixo do ponto isoelétrico das respectivas proteínas. Do mesmo modo, as soluções que contêm um polissacarídeo catiônico (por exemplo, quitosana) e um polissacarídeo aniônico (por exemplo, alginato) têm a capacidade de formar coacervados (AUGUSTIN; HEMAR, 2009).

Entretanto, a sensibilidade ao pH e à força iônica é um dos fatores que limitam a utilização de coacervados. Dessa forma, para aumentar a resistência dos coacervados, o invólucro formado pelos hidrocolóides pode então ser reticulado utilizando um agente de reticulação químico ou enzimático apropriado. O glutaraldeído é um agente de reticulação eficaz, mas existem problemas legais referentes à sua utilização. Nesse sentido, reticuladores enzimáticos, tais como a transglutaminase, são mais aceitáveis na indústria de alimentos e, recentemente, polifenóis extraídos de plantas têm sido utilizados para reticular coacervados à base de gelatina (GOUIN, 2004; AUGUSTIN; HEMAR, 2008).

A técnica de coacervação complexa apresenta inúmeras vantagens quando comparada à outras técnicas como versatilidade, eficiente controle no tamanho da partícula, possibilidade de se trabalhar com biopolímeros com ausência de solventes orgânicos e condições brandas de temperatura no processamento (ASSIS, ZAVAREZE, PRENTICE-HERNÁNDEZ; SOUZA-SOARES, 2012; MENEZES et al., 2013; JAMEKHORSHID; SADRAMELI; 
Tabela 2 - Materiais encapsulantes mais utilizados na encapsulação de probióticos

\begin{tabular}{lc}
\hline Fonte & Exemplo \\
\hline Carboidratos & Amido, dextrinas, açúcar, celuloses, acetato \\
ftalato de celulose (CAP) \\
Gomas & Goma arábica, alginato de sódio, carragena \\
Lipídeos & Monoglicerídeos e diglicerídeos, óleos e \\
Proteínas & gorduras \\
Quitosana & Glúten, caseína, gelatina, albumina \\
& Fonte alternativa extraída da casca de \\
\hline
\end{tabular}

Fonte: SUAVE (2006); MENEZES et al. (2013)

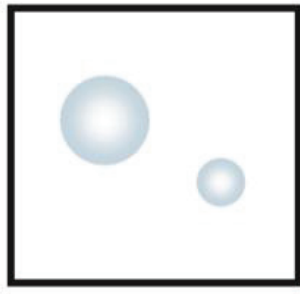

(a)

Agente ativo

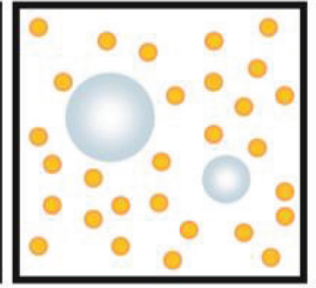

(b)

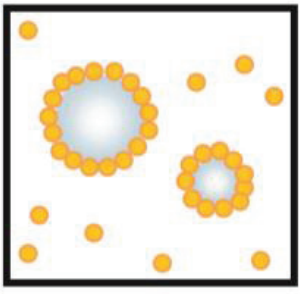

(c)

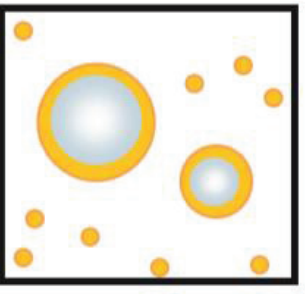

(d)

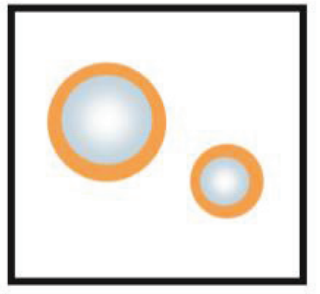

(e)

Camada polimérica

Camada polimérica endurecida

Figura 2 - Representação esquemática das etapas do processo de microencapsulação por coacervação. (a)

Dispersão do agente ativo a ser encapsulado em uma solução do polímero; (b) Indução da coacervação, formando gotículas de coacervado; (c) Deposição das gotículas de coacervado em torno dos núcleos contendo

o princípio ativo; (d) Coalescência das gotículas de coacervado para formar uma camada polimérica; (e) Endurecimento da camada polimérica por meio da difusão do solvente.

Fonte: SUAVE (2006)

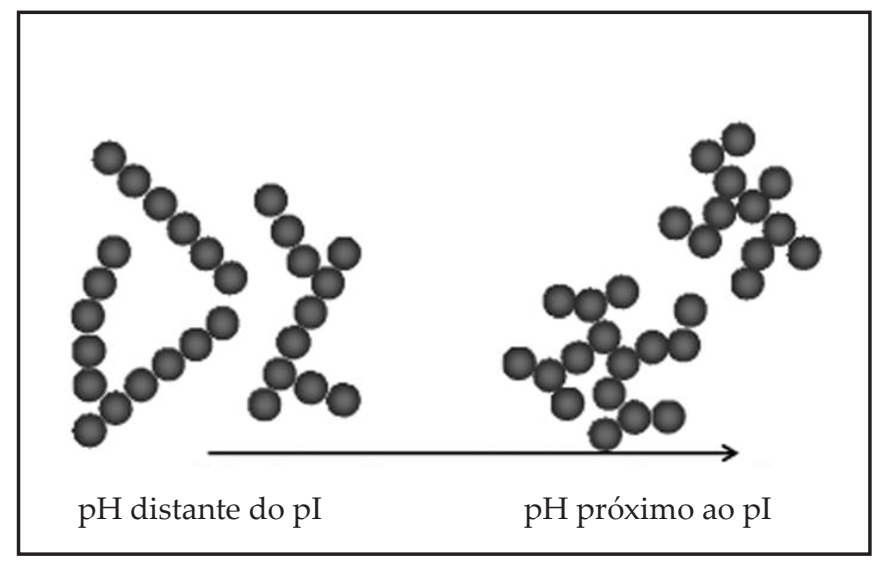

Figura 3 - Representação esquemática de agregados de proteínas filamentosas ou partículas sob diferentes condições de $\mathrm{pH}$. pI é o ponto isoelétrico da proteína.

Fonte: AUGUSTIN; HEMAR (2009) 
FARID, 2014).

No entanto, uma das limitações da coacervação complexa é a dificuldade de encapsulação de compostos hidrofílicos, sendo a técnica mais apropriada para os compostos hidrofóbicos como materiais de núcleo (MENDANHA et al., 2009). De acordo com Gouin (2004), apesar das vantagens intrínsecas e as propriedades únicas da coacervação em comparação com outros processos de encapsulação, os principais problemas a encarar quando se trata de comercialização de um ingrediente alimentício coacervado, é o processo dispendioso e complexo.

\subsection{Aplicações da coacervação complexa para probióticos}

A técnica de coacervação complexa ainda está sendo muito pesquisada na encapsulação de bactérias probióticas, assim, atualmente, os dados encontrados na literatura são pouco difundidos.

OLIVEIRA et al. (2007) utilizaram a coacervação complexa para encapsular B. lactis (B1 01) e L. acidophilus (LAC 4) em caseína/pectina. O objetivo desse estudo foi avaliar a resistência desses microrganismos e das microcápsulas em relação ao processo de secagem por leito de jorro, vida de prateleira e tolerância in vitro ao $\mathrm{pH}$ ácido, simulando o trato gastrointestinal. O método de leito de jorro mostrou-se adequado para a secagem das microcápsulas, pois a redução na viabilidade dos microrganismos foi somente 0,3 ciclos logarítmicos. Em relação à vida de prateleira, sob armazenamento a $7^{\circ} \mathrm{C}$, as microcápsulas contendo $\mathrm{Bl} 01$ permaneceram estáveis por 90 dias, já as microcápsulas com LAC 4 permaneceram estáveis por 60 dias. Ambos os microrganismos quando armazenados a $37^{\circ} \mathrm{C}$ tiverem redução de pelo menos 3 ciclos logarítmicos em 30 dias. Em relação à sobrevivência em diferentes valores de $\mathrm{pH}$, as células de LAC 4 microencapsuladas apresentaram sensibilidade, ocorrendo reduções de 2,7 ciclos logarítmicos em $\mathrm{pH} 3$ e a perda de viabilidade em pH 1. Entretanto, as células de $\mathrm{Bl} 01$ microencapsuladas foram menos sensíveis, reduzindo 1 ciclo logarítmico em pH 3 e 2,6 ciclos logarítmicos em $\mathrm{pH} 1$.

SHOJI et al. (2013) utilizaram a coacervação complexa para encapsular L. acidophilus em pectina/caseína, aplicando as microcápsulas em iogurte de leite de búfala. O objetivo primário desse estudo foi realizar a microencapsulação de L. acidophilus por coacervação complexa seguida de secagem por liofilização. O objetivo secundário foi avaliar a viabilidade do L. acidophilus microencapsulado durante armazenamento e sua resistência a valores de $\mathrm{pH}$ similares ao estômago humano. De acordo com os resultados, L. acidophilus demonstrou ser resistente à liofilização, pois redução de apenas 0,7 ciclos logarítmicos. Em relação ao armazenamento que variou de 30 a 120 dias, os resultados indicaram que a viabilidade do L. acidophilus foi maior nas microcápsulas armazenadas sob refrigeração, pois a $7^{\circ} \mathrm{C}$ a contagem dos microrganismos variou entre 9,04 e 7,23 log UFC.g-1, enquanto que a $37^{\circ} \mathrm{C}$ os microrganismos apresentaram uma perda significativa na viabilidade após 30 dias, de 9,70 para 6,47 log UFC.g-1. Já em relação à sobrevivência dos microrganismos em diferentes valores de $\mathrm{pH}$, comparando os microrganismos na forma livre e microencapsulados, pode-se observar que em $\mathrm{pH} 1$ no tempo inicial, os probióticos livres foram totalmente viáveis, entretanto, os microrganismos microencapsulados não apresentaram viabilidade. Após 3h, os microrganismos livres apresentaram redução de 3 ciclos logarítmicos. No entanto, observou-se um comportamento diferente em pH 3, os microrganismos livres apresentaram redução menos intensa e os microrganismos microencapsulados tiveram uma melhor performance, permanecendo viáveis. Por fim, a adição de L. acidophilus microencapsulado ao iogurte resultou em menor declínio de $\mathrm{pH}$ e valores menores pós-acidificação, comparando às células livres, indicando que o processo de encapsulação resulta em menor atividade metabólica dos microrganismos.

\section{Conclusões}

Diante do exposto, pode-se observer que a coacervação complexa é uma técnica promissora e demonstra grande potencial para a encapsulação de bactérias probióticas, ressaltando que, devido aos parâmetros envolvidos, mais estudos devem ser realizados com o intuit de otimizar o processo.

\section{Agradecimentos}

$$
\text { À Capes. }
$$

\section{Referências}

ASSIS, L. M.; ZAVAREZE, E. R.; PRENTICEHERNÁNDEZ, E. R.; SOUZA-SOARES, L. A. Revisão: Características de nanopartículas e potenciais aplicações em alimentos. Campinas, v. 15, n. 2, p. 99-109, 2012.

AUGUSTIN, M.A.; HEMAR, Y. Nano- and microstructured assemblies for encapsulation of food ingredientes. Chem. Soc. Rev., v. 38, p. 902-912, 2009.

AZEREDO, H. M. C. Encapsulação: aplicação à tecnologia de alimentos. Alimentos e Nutrição, Araraquara, v. 16, n. 1, p. 89-97, jan./mar. 2005.

BRASIL. Lista de alegações de propriedade funcional aprovadas. Brasília, 2008. Disponível em: <http://www.anvisa.gov.br/alimentos/comissoes/ tecno_lista_alega.htm>. Acesso em 17/09/2015.

BURGAIN, J.; GAIANI, C.; LINDER, M.; SCHER, 
J. Enacpsulation of probiotic living cells: From laboratory scale to industrial applications. Journal of Food Engineering, v. 104, p. 467-483, 2011.

CHITPRASERT, P.; SUDSAI, P.; RODKLONGTAN, A. Aluminum carboxymethyl cellulose-rice bran microcapsules: Enhancing survival of Lactobacillus reuteri KUB-AC5. Carbohydrate Polymers, v. 90 (1), p. 78-86, setembro, 2012.

DAIRIKI, J. K. Probióticos na aquicultura. $\mathrm{V}$ Encontro de negócios da aquicultura na Amazônia - Enaq - AM, Manaus, AM, 2013.

GOUIN, S. Microencapsulation: Industrial appraisal of existing technologies. Food Sci. Technol. 15, 330-347, 2004.

FAVARO-TRINDADE, C.S., PINHO, S.C. and ROCHA, G.A. Microencapsulação de ingredientes alimentícios. Braz. J. Food Technol. 11, 103-112, 2008.

FOOD AND AGRICULTURE ORGANIZATION OF THE UNITED NATIONS, WORLD HEALTHORGANIZATION. Evaluation of health and nutritional properties of probiotics in food including powder milk with live lactic acid bacteria. Córdoba, 2001. 34p. Disponível em: $<$ http://www.who.int/foodsafety/publications/fs_ management/en/probiotics.pdf $>$. Acesso em: 17/09/2015. [Report of a Joint FAO/WHO Expert Consultation].

FULLER, R. Probiotics in man and animals. Journal Applied Bacteriological, Oxford, v.66, p.365-378, 1989.

GOUIN, S. Microencapsulation: industrial appraisal of existing Technologies and trends. Trends in Food Science \& Technology, v. 15, p. 330-347, 2004.

JAMEKHORSHID, A.; SADRAMELI, S. M.; FARID, M. A review of microencapsulation methods of phase change materials (PCMs) as a thermal energy storage (TES) médium. Renewable and Sustainable Energy Reviews, v. 31, p. 531-542, 2014.

KOMATSU, T. R.; BURITI, F. C. A.; SAAD, S. M. I. Inovação, persistência e criatividade superando barreiras no desenvolvimento de alimentos probióticos. Revista Brasileira de Ciências Farmacêuticas, vol. 44, n. 3, jul./set., 2008.

MENDANHA,D.V.;ORTIZ, S.E.M.; FAVARO-TRINDADE, C.S.; MAURI, A.; MONTERREY-QUINTERO, E.S.; THOMAZINI, M. Microencapsulation of casein hydrolysate by complex coacervation with SPI/ pectin. Food

Res. Intern. v. 42, p. 1099-1104, 2009.

MENEZES, C. R.; BARIN, J. S.; CICHOSKI, A.
J.; ZEPKA, L. Q.; JACOB-LOPES, E.; FRIES, L. L. M.; TERRA, N. N. Microencapsulação de probióticos: avanços e perspectivas. Ciência Rural, Santa Maria, v.43, n.7, p.1309-1316, julho, 2013.

OLIVEIRA, A. C. J. Viabilidade de Lactobacillus acidophillus e Bifidobacterium lactis microencapsulados por coacervação, seguida de secagem por spray-drying e leito de jorro. Dissertação de Mestrado, Universidade de São Paulo, Faculdade de Ciências Farmacêuticas de Ribeirão Preto, São Paulo, 2006. Disponível em <http:// www.teses.usp.br/teses/disponiveis/60/60137/tde10052007-103644/pt-br.php>. Acesso em: 20/09/2015.

OLIVEIRA, A. C.; MORETTI, T. S.; BOSCHINI, C.; BALIERO, J. C. C.; FREITAS, L. A. P. 2; FREITAS, O.; FAVARO-TRINDADE, C. S. Microencapsulation of B. lactis (BI 01) and L. acidophilus (LAC 4) by Complex Coacervation Followed by Spouted-Bed Drying. Drying Technology, v. 25, p. 1687-1693, 2007.

RANADHEERA, R. D. C. S.; BAINES, S. K.; ADAMS, M. C. Importance of food in probiotic efficacy. Food Research International, v. 43, p. 1-7, 2010.

SAAD, S. M. I. Probióticos e prebióticos: o estado da arte. Revista Brasileira de Ciências Farmacêuticas, vol. 42, n. 1, jan./mar., 2006.

SILVA, D.F.; FAVARO-TRINDADE, C.S.; ROCHA, G.A.; THOMAZINI, M. Microencapsulation of lycopene by gelatin-pectin complex coacervation. Journal of Food Processing and Preservation, v. 36, p. 185-190, 2011.

SHOJI, A. S.; OLIVEIRA, A. C.; BALIEIRO, J. C. C.; FREITAS, O.; THOMAZINI, M.; HEINEMANN, R. J. B.; OKURO, P. K.; FAVARO-TRINDADE, C. S. Viability of L. acidophilus microcapsules and their application to buffalo milk yoghurt. Food and Bioproducts Processing, v. 91, p. 83-88, 2013.

SUAVE, J.; DALL'AGNOL, E. C.; PEZZIN, A. P. T.; SILVA, D. A. K.; MEIER, M. M.; SOLDI, V. Microencapsulação: Inovação em diferentes áreas. Revista Saúde e Ambiente / Health and Environment Journal, v. 7, n. 2, p. 12-20, 2006.

SULTANA, K.; GODWARD, G.; REYNOLDS, N.; ARUMUGASWAMY, R.; PEIRIS, P.; KAILASAPATHY, K. Encapsulation of probiotic bacteria with alginatestarch and evaluation of survival in simulated gastrointestinal conditions and in yoghurt. International Journal of Food Microbiology, v. 62, p. 47-55, 2000. 